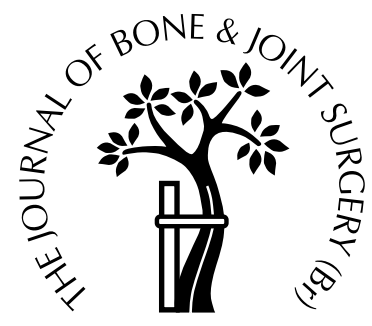

\title{
Ligament repair and reconstruction in traumatic dislocation of the knee
}

\author{
R. Y. L. Liow, M. J. McNicholas, J. F. Keating, R. W. Nutton \\ From the Royal Infirmary Edinburgh, Scotland
}

W e treated 21 patients with 22 dislocations of the knee by repair or reconstruction of all injured ligaments. Eight knees were treated in the acute phase (less than two weeks after injury); the remainder were treated more than six months after injury (6 to 72). Reconstructions were carried out with a combination of autograft and allograft tendons and by direct ligament repair where possible. At a mean follow-up of 32 months (11 to 77) the mean Lysholm score was 87 (81 to 91) in the acute group and 75 (53 to 100) in the delayed group. The mean Tegner activity rating was 5 in the acute group and 4.4 in the delayed group.

The International Knee Documentation Committee assessment revealed no differences between the two groups. Instrumented testing of knee stability indicated better results for anterior cruciate ligament reconstructions which had been undertaken in the acute phase, but no difference in the outcome of posterior cruciate ligament reconstructions. There was no difference in the loss of knee movement between the two groups. Although the differences were small, the outcome in terms of overall knee function, activity levels and anterior tibial translation were better in those knees which had been reconstructed within two weeks of injury.

J Bone Joint Surg [Br] 2003;85-B:845-51. Received 25 October 2002; Accepted 23 April 2003

R. Y. L. Liow, FRCS (Trauma and Orth), Consultant Trauma and Orthopaedic Surgeon

Middlesbrough General Hospital, Ayresome Green Lane, Middlesbrough TS5 5AZ, UK.

M. J. McNicholas, MD, FRCS (Trauma and Orth), Consultant Trauma and Orthopaedic Surgeon

North Cheshire Hospitals NHS Trust, Warrington General Hospital, Lovely Lane, Warrington, Cheshire WA5 1QG, UK.

J. F. Keating, MPhil, FRCS Ed (Orth), Consultant Orthopaedic Surgeon Department of Orthopaedic Trauma, Royal Infirmary, Lauriston Place, Edinburgh EF3 9YW, UK.

R. W. Nutton, FRCS, Consultant Orthopaedic Surgeon,

Royal Infirmary Edinburgh, Little France, Old Dalkeith Road, Edinburgh EH16 4SU, UK.

Correspondence should be sent to Mr R. Y. L. Liow.

(C)2003 British Editorial Society of Bone and Joint Surgery doi:10.1302/0301-620X.85B6.13972 \$2.00
Traumatic dislocation of the knee, confirmed by clinical and radiological evidence of tibiofemoral disarticulation is a rare injury although this definition of dislocation may underestimate the true incidence. ${ }^{1}$ An injury to two or more of the main ligament structures - anterior cruciate ligament (ACL), posterior cruciate ligament (PCL), lateral ligament complex or medial collateral ligament (MCL), will result in a significant, but momentary displacement of the joint surfaces (Fig. 1). There is a risk of periarticular fracture and neurovascular damage and, if the extent of the injury is underestimated, the patient will develop symptoms of instability and in the long term, premature osteoarthritis.

The most effective treatment for traumatic dislocation of the knee remains controversial. Some surgeons have advocated POP immobilisation, ${ }^{2}$ while others have approached this complex problem by primary repair of all the injured structures. The results of this approach are disappointing, with a high incidence of persistent instability and loss of movement. ${ }^{3-9}$ The advent of reliable methods for reconstructing both cruciate ligaments by using autogenous tendons has seen a shift towards early bicruciate ligament reconstruction, either simultaneously or as a staged procedure. ${ }^{10-15}$

Experience in our unit suggests that knees which have undergone ligament reconstruction have better function than those which have been treated non-operatively. ${ }^{16} \mathrm{~A}$ protocol was established for the early repair of the collateral structures and reconstruction of both the ACL and PCL. Later referrals were subjected to a thorough assessment in order to determine the patterns of instability before reconstruction was undertaken. The purpose of this study was to evaluate the clinical results of this protocol, in which contemporary surgical techniques have been employed.

\section{Patients and Methods}

Between 1994 and 2001, 21 patients with 22 dislocations of the knee presented to our unit. A dislocation was defined as an acute injury resulting in complex, multidirectional instability. For inclusion in this study, multiple ligaments must have been injured, with at least two of the four major ligaments torn. ${ }^{17}$ All patients were managed by repair or reconstruction of the injured structures. Patients included both acute admissions and late referrals from outside the region. The details of the injuries are summarised in Table I. 


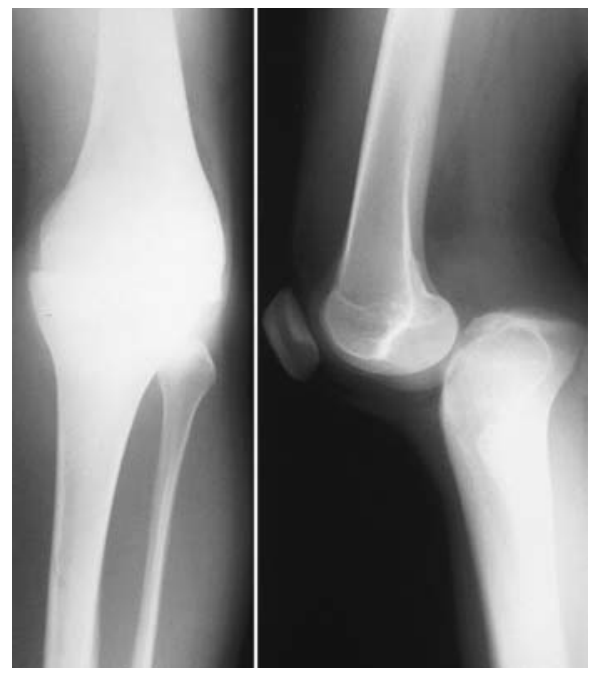

Fig. 1a

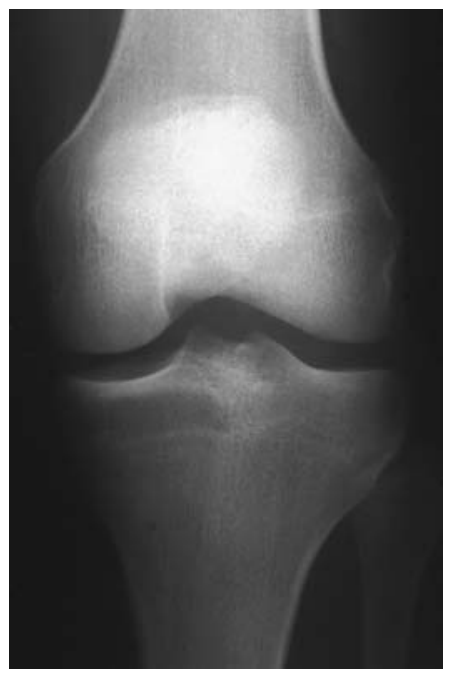

Fig. 1b

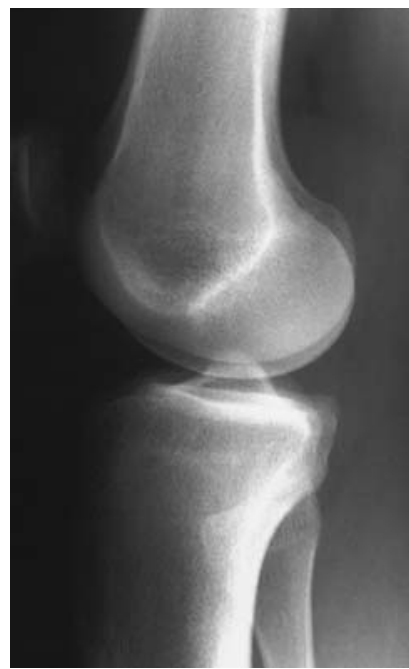

Fig. 1c

Radiographs showing dislocations of the knee. a) Anteroposterior (AP) and lateral radiographs of a 20-year-old woman (case 16) with an obvious dislocation. b) An AP and c) a lateral view of a 19-year-old man (case 4) who presented with the knee reduced. Examination under anaesthesia comfirmed ruptures of the ACL and posterolateral complex. Any injury that produces complete tears of two of the four ligament complexes is now regarded as a dislocation of the knee. ${ }^{17}$

Table I. Injury details of the 21 patients with traumatic dislocation of the knee

\begin{tabular}{|c|c|c|c|c|c|c|c|c|}
\hline \multirow[b]{2}{*}{ Case } & \multirow{2}{*}{$\begin{array}{l}\text { Age } \\
\text { (yrs) }\end{array}$} & \multirow[b]{2}{*}{ Gender } & \multirow{2}{*}{$\begin{array}{l}\text { Mechanism of } \\
\text { injury* }\end{array}$} & \multirow{2}{*}{$\begin{array}{l}\text { Associated injuries and } \\
\text { complications } \dot{\dagger}^{\dagger}\end{array}$} & \multirow[b]{2}{*}{ Early treatment } & \multicolumn{2}{|c|}{$\begin{array}{l}\text { Time interval before } \\
\text { definitive treatment }\end{array}$} & \multirow{2}{*}{$\begin{array}{l}\text { Follow-up } \\
\text { interval } \\
\text { (mths) }\end{array}$} \\
\hline & & & & & & Days & Months & \\
\hline \multicolumn{9}{|c|}{ Acute reconstruction } \\
\hline 1 & 25 & $\mathrm{~F}$ & Contact sport & & POP immobilisation & 7 & & 28 \\
\hline 2 & 22 & M & RTA & & & 13 & & 31 \\
\hline 3 & 30 & M & RTA & $\begin{array}{l}\text { Possible compartment syndrome, } \\
\text { blunt abdominal trauma, ISS }>15\end{array}$ & $\begin{array}{l}\text { Compartment pressure } \\
\text { monitoring, laparotomy }\end{array}$ & $\begin{array}{l}3 \text { (right knee) } \\
5 \text { (left knee) }\end{array}$ & & $\begin{array}{l}36 \\
36\end{array}$ \\
\hline 4 & 19 & M & Jump & & & 10 & & 18 \\
\hline 5 & 16 & M & Contact sport & & & 12 & & 8 \\
\hline 6 & 34 & M & Non-contact sport & & & 14 & & 8 \\
\hline 7 & 35 & M & Jump & $\begin{array}{l}\text { Peroneal nerve injury, marginal } \\
\text { medial tibial condyle fracture }\end{array}$ & $\begin{array}{l}\text { Examination under } \\
\text { anaesthesia, aspiration }\end{array}$ & 9 & & 11 \\
\hline \multicolumn{9}{|c|}{ Chronic reconstruction } \\
\hline 8 & 46 & $\mathrm{~F}$ & RTA & & $\begin{array}{l}\text { Examination under } \\
\text { anaesthesia, arthroscopy }\end{array}$ & & 12 & 20 \\
\hline 9 & 46 & M & RTA & Multiple injuries, ISS >15 & Stabilisation of fractures & & 13 & 42 \\
\hline 10 & 29 & M & Contact sport & & Early MCL repair & & 16 & 26 \\
\hline 11 & 43 & M & Contact sport & & & & 17 & 15 \\
\hline 12 & 21 & M & Trampolining & & & & 6 & 6 \\
\hline 13 & 18 & $\mathrm{~F}$ & RTA & & Early MCL repair & & 11 & 65 \\
\hline 14 & 22 & M & RTA & Contralateral tibial fracture & $\begin{array}{l}\text { Open reduction and internal } \\
\text { fixation tibia }\end{array}$ & & 30 & 39 \\
\hline 15 & 15 & M & RTA & & & & 60 & 27 \\
\hline 16 & 20 & $\mathrm{~F}$ & Trampolining & Popliteal artery injury & $\begin{array}{l}\text { Examination under } \\
\text { anaesthesia, external } \\
\text { fixation, vascular graft }\end{array}$ & & 6 & 84 \\
\hline 17 & 39 & $\mathrm{~F}$ & RTA & $\begin{array}{l}\text { Open dislocation, contralateral } \\
\text { femoral fracture }\end{array}$ & $\begin{array}{l}\text { Wound debridement, open } \\
\text { reduction and internal } \\
\text { fixation femur }\end{array}$ & & 27 & 77 \\
\hline 18 & 26 & M & Contact sport & & & & 63 & 11 \\
\hline 19 & 19 & M & Contact sport & & & & 9 & 18 \\
\hline 20 & 18 & M & Jump & & $\begin{array}{l}\text { Examination under } \\
\text { anaesthesia, repair LCL }\end{array}$ & & 60 & 44 \\
\hline 21 & 21 & M & RTA & ISS $>15$, brachial plexus injury & & & 72 & 56 \\
\hline
\end{tabular}

*RTA, road traffic accident

$\dagger$ †SS, injury severity score 
Table II. Details of surgical reconstructions of ACL, PCL, MCL, LCL and the posterolateral corner (PL) for traumatic dislocation of the knee

\begin{tabular}{|c|c|c|c|c|c|c|}
\hline \multirow[b]{2}{*}{ Case } & \multirow[b]{2}{*}{ Injured structures } & \multicolumn{5}{|l|}{ Reconstructions } \\
\hline & & ACL & PCL & MCL & $\mathbf{L C L}$ & $\begin{array}{l}\text { Posterolateral } \\
\text { corner }\end{array}$ \\
\hline \multicolumn{7}{|c|}{ Acute reconstruction } \\
\hline 1 & ACL, PCL, LCL, PL & Patellar autograft & Hamstring + augment $*$ & & Repair & Repair \\
\hline 2 & ACL, PCL, LCL, PL & Patellar allograft & Achilles allograft & & Repair & Repair \\
\hline 3 Right & ACL, PCL, MCL & Patellar autograft & Achilles allograft + augment* & Repair & & \\
\hline 3 Left & ACL, LCL, PL & Patellar autograft & & & Repair & $\begin{array}{l}\text { Biceps } \\
\text { advancement }\end{array}$ \\
\hline 4 & ACL, LCL, PL & Hamstring & & & Repair & Repair \\
\hline 5 & ACL, LCL, PL & Hamstring & & & Repair & Repair \\
\hline 6 & ACL, LCL, PL & Hamstring & & & Repair & Repair \\
\hline 7 & PCL, LCL, tibial fracture & & Achilles allograft & & Repair & \\
\hline \multicolumn{7}{|c|}{ Chronic reconstruction } \\
\hline 8 & ACL, PCL, LCL, PL & Patellar allograft & Achilles allograft + augment* & & \multirow{2}{*}{\multicolumn{2}{|c|}{$\begin{array}{l}\text { Larson's reconstruction with } \\
\text { hamstring } \\
\text { Larson's reconstruction with } \\
\text { hamstring }\end{array}$}} \\
\hline 9 & ACL, PCL, LCL, PL & Patellar allograft & Achilles allograft + augment* & & & \\
\hline 10 & ACL, PCL, LCL, PL & Hamstring & Achilles allograft + augment* & & $\begin{array}{l}\text { Acute } \\
\text { repair }\end{array}$ & $\begin{array}{l}\text { Biceps } \\
\text { advancement }\end{array}$ \\
\hline 11 & ACL, PCL, LCL, PL & Patellar autograft & Achilles allograft + augment* & & \multicolumn{2}{|c|}{$\begin{array}{l}\text { Larson's reconstruction with } \\
\text { hamstring }\end{array}$} \\
\hline 12 & ACL, PCL, MCL & Hamstring & Achilles allograft + augment* & & & \\
\hline 13 & ACL, PCL, MCL & Patellar autograft & Patellar allograft & & & \\
\hline 14 & ACL, PCL, MCL & Patellar autograft & Achilles allograft + augment* & Femoral advancement & & \\
\hline 15 & ACL, PCL, MCL & Patellar autograft & Achilles allograft + augment* & Tibial advancement & & \\
\hline 16 & ACL, PCL & Patellar autograft & Achilles allograft & & & \\
\hline 17 & ACL, PCL & Patellar autograft & Achilles allograft + augment* & & & \\
\hline 18 & ACL, PCL, LCL, PL & Patellar autograft & & & \multicolumn{2}{|c|}{$\begin{array}{l}\text { Larson's reconstruction with } \\
\text { hamstring }\end{array}$} \\
\hline 19 & ACL, LCL, PL & Hamstring & & & \multicolumn{2}{|c|}{$\begin{array}{l}\text { Trouser Achilles allograft } \\
\text { with augmentation* }\end{array}$} \\
\hline 20 & ACL, LCL, PL & Hamstring & & & \multicolumn{2}{|c|}{$\begin{array}{l}\text { Trouser Achilles allograft } \\
\text { with augmentation* }\end{array}$} \\
\hline 21 & PCL, MCL & & Achilles allograft + augment* & Semitendinosus & & \\
\hline
\end{tabular}

*augment: graft reinforcement with Leeds-Keio neoligament

Operative strategy and techniques. The senior authors (JFK and RWN) favoured early repair and reconstruction. For this reason, seven patients (eight knees) underwent exploration and repair or reconstruction within 14 days of injury. In this group, the collateral ligaments and posterolateral corner were repaired when indicated, and the cruciate ligaments reconstructed. Both the ACL and PCL were reconstructed simultaneously if required. Fresh frozen allografts were used as shown in Table II. Five patients had reconstructions within 12 months of injury and the remainder had late reconstructions, more than one year from injury.

The pattern of ligament disruption was defined at the time of surgery in the acute referrals. The remainder underwent detailed examination in order to assess the integrity of the ACL, PCL, MCL, lateral collateral ligament (LCL) and posterolateral complex. MR scans were obtained and the patterns of instability were finally confirmed on examination under anaesthesia immediately prior to the reconstructive operations. The patterns of instabilities are summarised in Table II.

Collateral ligaments were repaired if there was a midsubstance disruption, or reattached if avulsed from their insertion (Fig. 2). Tears of the LCL often accompanied disruption of the posterolateral complex. In the acute setting, the posterolateral structures were repaired (five patients), and, in one patient, the repair was augmented with a biceps femoris advancement. Late reconstructions of the posterolateral corner used the modified Larson repair (four knees) with hamstring autografts or a 'trouser legs' tendo Achillis allograft technique (two patients). ${ }^{18,19}$

The cruciate ligament reconstructions were through an open approach when undertaken early and arthroscopically when carried out late. For anterior cruciate reconstruction we used patellar tendon-bone autografts in ten patients, host four-strand hamstrings in seven, and patellar tendon-bone allograft in three patients (Table II). PCL reconstructions were undertaken in 15 knees, 13 with tendo Achillis allograft. Ten were augmented with a synthetic ligament. One PCL reconstruction required autogenous hamstrings augmented with a prosthetic ligament. In combined ACL and PCL reconstructions, the PCL grafts were tightened in order to re-establish the central pivot of the knee ${ }^{20}$ before the ACL grafts were secured. In the event of an additional MCL disruption, its repair or reconstruction followed the bicruciate reconstruction. ${ }^{21}$ With the combination of ACL, PCL, LCL and posterolateral injuries, the PCL was stabilised 


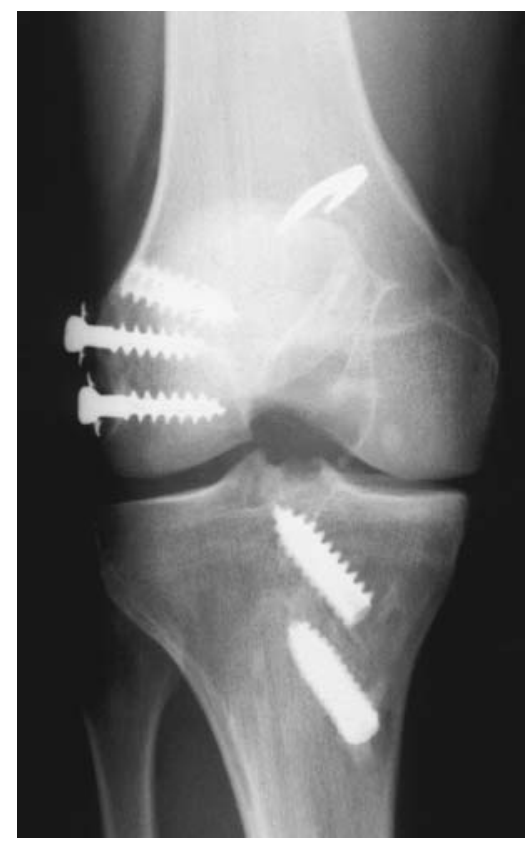

Fig. 2a

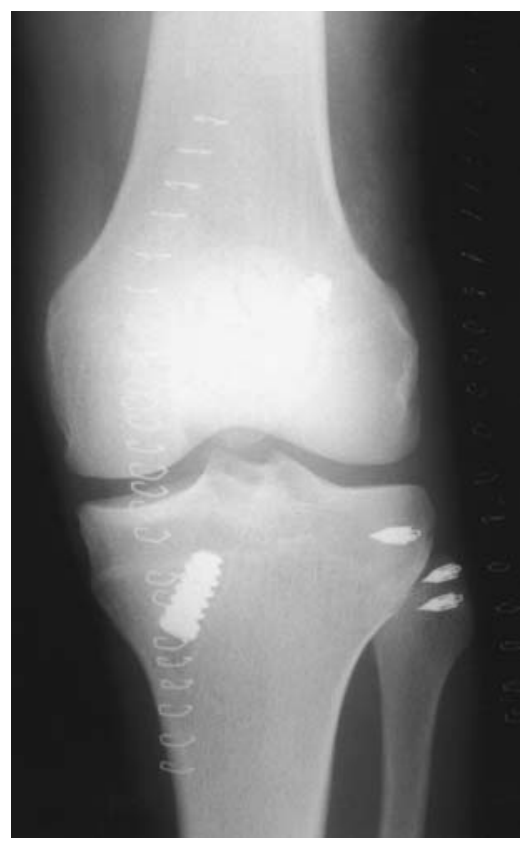

Fig. 2b

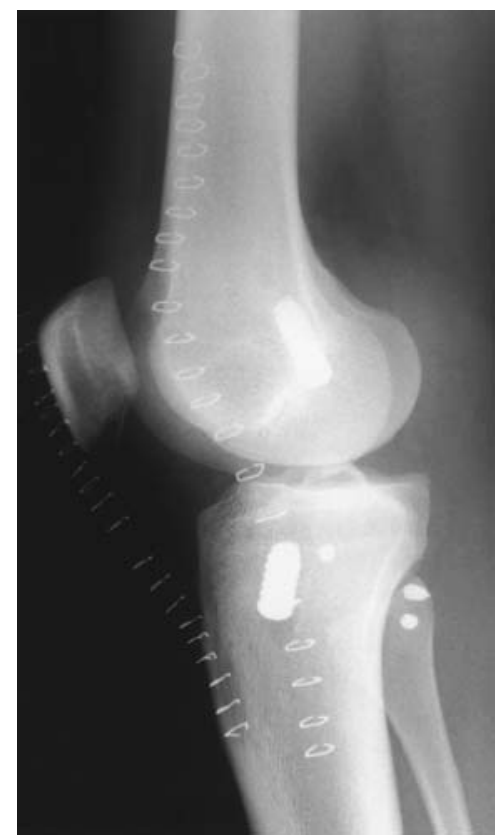

Fig. 2c

Acute surgery involved repair of the collateral ligaments and posterolateral complex, with reconstruction of the cruciate ligaments. The lateral collateral ligament and posterolateral structures were repaired with ligament washers as shown in the AP radiograph of case 2 (a) and suture anchors as shown in the AP and lateral radiographs of case 4 (b and c).

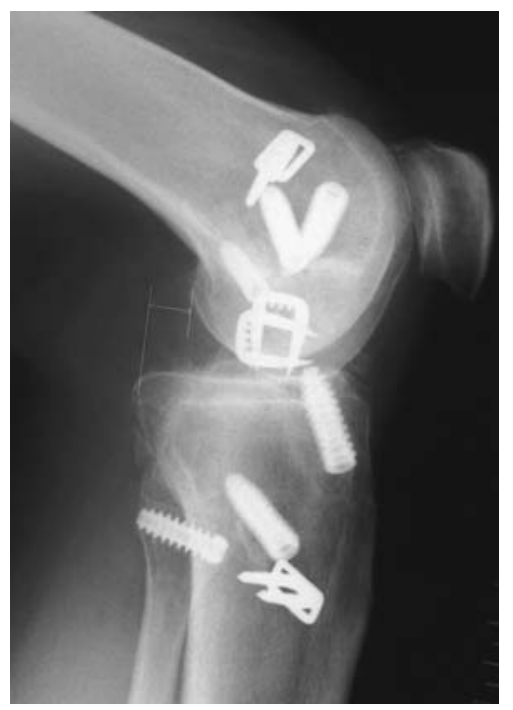

Fig. 3

PCL reconstructions were assessed with stress radiographs. The technique was modified from that of Staubli et al. ${ }^{25}$ The displacement of the tibia against the femur was measured.

first, followed by the LCL and posterolateral corner, before the final fixation of the ACL graft. ${ }^{22}$

Postoperative management entailed protection of the knee in a hinged knee brace for eight to 12 weeks. Patients were initially allowed flexion to $30^{\circ}$ for four weeks, increasing progressively to $90^{\circ}$ by the twelfth postoperative week. They were allowed touch weight-bearing mobilisation for six weeks, progressing to full weight-bearing by three months. We stressed the avoidance of open chain active knee flexion in the early healing phase in order to minimise the forces which may sublux the tibia posteriorly and compromise the PCL reconstruction. Bracing was discontinued at three months.

Assessment. An independent observer made a detailed objective and subjective assessment of all patients. This comprised a physical examination which included measurement of the range of knee movement with a goniometer, instrumented Lachman and posterior drawer tests at $80^{\circ}$ using the Rolimeter (Aircast, Summit, New Jersey), assessment of opening of the joint line on varus and valgus stressing, the 'dial test' for posterolateral instability and the pivot and reverse pivot tests. ${ }^{23,24}$

In order to evaluate the competence of the PCL reconstruction, we employed a radiological technique modified from that of Stabuli, Noesberger and Jakob. ${ }^{25}$ This comprised a posterior stress lateral radiograph at $80^{\circ}$ of knee flexion with a $10 \mathrm{~kg}$ weight against the tibia in order to assess the translation of the tibia relative to the femur (Fig. 3). ${ }^{25,26}$

Knee function was assessed using the International Knee Documentation Committee (IKDC) $\operatorname{chart}^{27}$ and the Lysholm Score. ${ }^{28}$ Physical activity levels were measured using the Tegner Activity scale. ${ }^{29}$ 
Results

We assessed 21 patients ( 22 knees) at a mean follow-up of 32 months (11 to 77). The mean age at the time of injury was 27.7 years (15 to 46). There were 16 men and five women. The causes of injury and the interval between injury and surgery are shown in Table I. Three patients had multiple injuries (Injury Severity Score $>15$ ). One had a concomitant disruption of the popliteal artery which required a vascular reconstruction and one had a common peroneal nerve injury.

Nine $(41 \%)$ of the dislocations were documented radiologically, while four (18\%) were recognised clinically and had undergone immediate reduction. The remaining nine $(41 \%)$ were recognised as having severe, acute, complex ligamentous injuries either on clinical examination, MRI or examination under anaesthesia in the days after their admission. Seven patients (36\%) (eight knees) underwent surgical treatment in the acute period, between two and 14 days. The remaining $14(64 \%)$ were late referrals and underwent reconstruction for chronic instability at six to 72 months after injury. Details of the injured structures and reconstructions are shown in Table II.

The assessment of knee function using the IKDC form showed that eight knees were grade B or 'nearly normal', nine grade $\mathrm{C}$ or 'abnormal' and five grade $\mathrm{D}$ or 'severely abnormal'. No knees were grade A or 'normal'. Three of the eight knees which were treated acutely scored grade B compared with five of the 14 knees which underwent a delayed reconstruction. The mean Lysholm score for all knees was 79 points (53 to 100) with acute knees scoring a mean of 87 points (81 to 91) and late reconstructions a mean of 75 points (53 to 100). All acutely treated knees had a Lysholm score of $>80$ compared with only 5 of $14(36 \%)$ of chronically treated knees. The mean Tegner activity level was 4.6 (1 to 7). Five acute knees had levels $\geq 5$, compared with seven of the delayed reconstructions. The mean Tegner level was 5 (3 to 7) following early reconstruction and 4.4 (1 to 7) following late reconstruction.

Knee movement was measured with a goniometer. The mean loss of extension was $8^{\circ}$ (acute knees, $10^{\circ}$; late reconstructions, $7^{\circ}$ ) and the mean loss of flexion was $7^{\circ}$ (acute knees, $4^{\circ}$; late reconstructions, $8^{\circ}$ ). One patient who underwent an early reconstruction developed arthrofibrosis and subsequently required a manipulation under anaesthetic.

Instrumented testing of ACL function was undertaken on 20 knees after ACL reconstruction. No knee had less than 3 $\mathrm{mm}$ of side-to-side difference, $15 \mathrm{knees}$ had 3 to $5 \mathrm{~mm}$ difference and five knees had more than $10 \mathrm{~mm}$. Six of the seven acute reconstructions had 3 to $5 \mathrm{~mm}$ difference on arthrometry compared with nine of 13 delayed reconstructions. PCL reconstructions were carried out in 15 knees. No knee had 0 to $3 \mathrm{~mm}$ side-to-side difference using the posterior stress test, three knees had 3 to $5 \mathrm{~mm}$ side-to-side difference, eight had 6 to $10 \mathrm{~mm}$ and four had more than 10 $\mathrm{mm}$ difference. Three of the four acutely treated knees had less than $10 \mathrm{~mm}$ difference while eight of the 11 chronic reconstructions achieved a similar result. The pivot shift test was negative in six knees and Grade 1 positive (a 'glide' of movement) in the remainder. The 'dial' test, at $30^{\circ}$ and $90^{\circ}$ of knee flexion, was negative (less than $15^{\circ}$ of difference between the sides) for all knees.

Collateral ligament function was estimated by manual clinical testing at $20^{\circ}$ of flexion. Of the 14 knees with a LCL injury, seven had 3 to $5 \mathrm{~mm}$ of opening of the joint line and seven had $>5 \mathrm{~mm}$. In the seven knees with injury to the MCL, three had 3 to $5 \mathrm{~mm}$ of opening of the joint line and four had $>5 \mathrm{~mm}$.

\section{Discussion}

The definition of dislocation of the knee which was used in this study differs from that used in earlier reports, which required clinical or radiological evidence of dislocation. ${ }^{7,8,30}$ More recent studies have altered the definition to include all knee ligament injuries, which involve two or more main ligament structures. ${ }^{1,17}$ This appears to be appropriate as severe injuries may cause a momentary dislocation, which reduces spontaneously. This may result in severe soft tissue disruption, but without clinical or radiological evidence of dislocation. ${ }^{5,31}$

Opinions on the best method of treatment of an acute dislocation of the knee vary widely. Advocates of a nonsurgical approach recommend POP immobilisation after reduction of the dislocation and vascular repair if this is required. ${ }^{2}$ Others have reported a poor outcome of conservative treatment and have recommended early surgical exploration and attempted repair of all damaged ligaments. ${ }^{6}$ Repair of midsubstance ligamentous tears has generally been unsuccessful, although better results have been obtained following reattachment when the ligaments have been avulsed from their insertions. ${ }^{9}$

Recent developments in knee ligament reconstructive surgery for ACL and PCL tears using graft augmentation have been applied to reconstruction for acute dislocation and chronic complex instability of the knee. In addition, the use of allograft tendons has addressed the problem of the morbidity which is created by the use of autogenous tendons from the same leg, although harvesting tendons from the opposite leg remains an option. The risk of arthrofibrosis is a major concern following an acute reconstruction, particularly if this involves both cruciate ligaments. Some authors recommend reconstruction of the PCL and collateral ligament injuries alone, and defer ACL reconstruction until the patient develops rotatory instability. This is said to be rare. ${ }^{10-12,32}$ Others advocate reconstruction of all injured ligaments, including the ACL, and employ early, controlled range of movement exercises in a brace, ${ }^{13,14,33}$ although Shapiro and Freedman ${ }^{15}$ acknowledged that arthrofibrosis and heterotopic bone formation may occur.

This study reports our experience with reconstruction of all the injured ligaments in a group of patients with a major 
knee injury who were treated either acutely, within two weeks of injury, or by delayed reconstruction. We have previously reported better results with reconstruction than with nonsurgical treatment after dislocation of the knee and wished to determine if early surgical repair produced better results than late reconstruction. ${ }^{16}$ Knee function, as measured by the IKDC scale, rated no knee as 'normal' (Grade A) and eight knees as 'near normal' (Grade B). This poor result may be due to the harsh standards set by the IKDC scale compared with the Lysholm score. The Lysholm score is more subjective, and resulted in a mean score of 79 of a maximum of 100 points, with $60 \%$ of knees rated above 80 points. The Tegner activity scale, which rates physical activities as being between 0 and 10 , revealed that $54 \%$ of patients had a rating $\geq 5$. All knees which were treated acutely had a Lysholm score of $>80$ and a mean Tegner activity level of 5 . This compared with $36 \%$ of the chronic reconstructions which had a Lysholm score of $>80$ and a mean Tegner activity rating of 4.4

For an objective measurement of knee stability we used arthrometry and stress radiography. For those knees in which an ACL reconstruction had been undertaken, anterior tibial translation was $<5 \mathrm{~mm}$ in $66 \%$. The results were better when the ACL had been reconstructed in the acute phase, as six of seven knees had 3 to $5 \mathrm{~mm}$ of anterior translation compared with nine of 13 knees which had undergone a delayed reconstruction. The results of PCL reconstruction were less satisfactory due to a persistent posterior tibial subluxation of $>5$ $\mathrm{mm}$ in 12 of 15 knees. There was no difference between acute or delayed reconstructions. The difficulty in abolishing posterior tibial subluxation when undertaking a PCL reconstruction has been highlighted previously and is thought to be due to stresses imposed upon the graft during the healing period by the posterior drawer effect which is created by the hamstring muscles and gravity. ${ }^{11,31}$ In addition, most of the patients with a PCL disruption had their PCL reconstructed with allograft tendon, which may be slower to incorporate than an autogenous graft. ${ }^{34}$

These results suggest that early repair or reconstruction of all injured ligaments may produce a better functional outcome and a more stable knee, although the risk of arthrofibrosis remains a concern. In this series, the mean loss of flexion and extension in the acute group was $4^{\circ}$ and $10^{\circ}$, respectively, compared with $4^{\circ}$ and $7^{\circ}$ in the late group. These results do not support the view that early intervention runs a higher risk of producing arthrofibrosis and loss of movement.

In summary, repair or reconstruction of the injured ligaments in patients with traumatic dislocation of the knee can improve the stability in these very unstable knees. Early, rather than delayed reconstruction produced better results in terms of function and stability without an increased risk of arthrofibrosis. In our experience, the management of a dislocated knee is a major surgical challenge and should only be undertaken by surgeons with extensive experience of knee ligament reconstruction.
No benefits in any form have been received or will be received from a commercial party related directly or indirectly to the subject of this article.

\section{References}

1. Brautigan B, Johnson DL. The epidemiology of knee dislocations. Clin Sports Med 2000;19:387-97.

2. Taylor AR, Arden GP, Rainey HA. Traumatic dislocation of the knee: a report of forty-three cases with special reference to conservative treatment. J Bone Joint Surg [Br] 1972;54-B:96-102.

3. Almekinders LC, Logan TC. Results following treatment of traumatic dislocations of the knee joint. Clin Orthop 1992;284:203-7.

4. Frassica FJ, Sim FH, Staeheli JW, Pairolero PC. Dislocation of the knee. Clin Orthop 1991;263:200-5.

5. Kennedy JC. Complete dislocation of the knee joint. J Bone Joint Surg [Am] 1963;45-A:889-904.

6. Meyers MH, Harvey JP Jr. Traumatic dislocation of the knee joint: a study of 18 cases. J Bone Joint Surg [Am] 1971;53-A:16-29.

7. Meyers MH, Moore TM, Harvey JP Jr. Traumatic dislocation of the knee joint. J Bone Joint Surg [Am] 1975;57-A:430-3.

8. Shields L, Mital M, Cave EF. Complete dislocation of the knee: experience at the Massachusetts General Hospital. J Trauma 1969;9:192215

9. Sisto DJ, Warren RF. Complete knee dislocation: a follow-up study of operative treatment. Clin Orthop 1985;198:94-101.

10. Schenk RC Jr. The dislocated knee. Instr Course Lect 1994;43:127-36.

11. Shelbourne KD, Porter DA, Clingman JA, McCarroll JR, Rettig AC. Low-velocity knee dislocation. Orthop Rev 1991;20:995-1004.

12. Yeh WL, Tu YK, Su JY, Hsu RW. Knee dislocation: treatment of highvelocity knee dislocation. J Trauma 1999;46:693-701.

13. Fanelli GC, Giannotti BF, Edson CJ. Arthroscopically assisted combined anterior and posterior cruciate ligament reconstruction. Arthroscopy 1996;12:5-14.

14. Noyes FR, Barber-Westin SD. Reconstruction of the anterior and posterior cruciate ligaments after knee dislocation: use of early protected postoperative motion to decrease arthrofibrosis. Am J Sports Med 1997;25:769-78

15. Shapiro MS, Freedman EL. Allograft reconstruction of the anterior and posterior cruciate ligaments after traumatic knee dislocation. Am J Sports Med 1995;23:580-7.

16. Werier J, Keating JF, Meek RN. Complete dislocation of the knee: the long-term results of ligamentous reconstruction. The Knee 1998;5:25560.

17. Taft TN, Almekinders LC. The dislocated knee. In: Fu F, ed. Knee surgery. Baltimore, Williams \& Wilkins, 1994:837-857.

18. Nutton RW. Complex knee instability. In: Allum RL, Ferguson CM, Thomas NP, eds. Clinical challenges in orthopaedics: the knee. Oxford, Isis Medical Media, 2000:75-94

19. Veltri DM, Warren RF. Operative treatment of posterolateral instability of the knee. Clin Sports Med 1994;13:615-27.

20. Hughston JC, Barret GR. Acute anteromedial rotatory instability: long-term results of surgical repair. J Bone Joint Surg [Am] 1983;65 A:145-53.

21. Klimkiewicz JJ, Petrie RS, Harner CD. Surgical treatment of combined injury to the anterior cruciate ligament, posterior cruciate ligament and medial structures. Clin Sports Med 2000;19:47992.

22. Fanelli GC. The treatment of combined anterior cruciate ligament-posterior cruciate ligament-lateral side injuries of the knee. Clin Sports Med 2000;19:493-502.

23. Balasch H, Schiller M, Friebel H, Hoffman F. Evaluation of anterior knee-joint instability with the Rolimeter. Knee Surg Sports Traumatol Arthrosc 1999;7:204-8.

24. Ganko A, Engebretsen L, Ozer H. The rolimeter: a new arthrometer compared with the KT 1000. Knee Surg Sports Traumatol Arthrosc 2000;8:36-9.

25. Staubli HU, Noesberger B, Jakob RP. Stress radiography of the knee: cruciate ligament function studied in 138 patients. Acta Orthop Scand 1992;249(Suppl):1-27.

26. Jakob RP. Posterior, posterolateral and posteromedial instability of the knee: diagnosis and treatment. In: Casteleyn PP, Duparc J, Fulford P, eds. European Instructional Course Lectures, 1995;2:27-40. 
27. International Knee Documentation Committee. Knee ligament injury and reconstruction evaluation. In: Aichroth PM, Cannon WD Jr, eds. Knee surgery: current practice. London, Martin Dunitz Ltd, 1992:759-760.

28. Lysholm J, Gillquist J. Evaluation of knee ligament surgery results with special emphasis on the use of a scoring scale. Am J Sports Med 1982;10:150-4.

29. Tegner Y, Lysholm J. Rating sytems in the evaluation of knee ligament injuries. Clin Orthop 1985;198:43-9.

30. Green NE, Allen BL. Vascular injuries accociated with dislocation of the knee. J Bone Joint Surg [Am] 1977;59-A:236-9.
31. Wascher DC, Dvirnak PC, DeCoster TA. Knee dislocations: initial assessment and implications for treatment. J Orthop Trauma 1997;11:525-9.

32. Shelbourne KD, Pritchard J, Rettig AC, McCarroll JR, Vanmeter CD. Knee dislocations with intact PCL. Orthop Rev 1992;21:607-11.

33. Wascher DC, Becker JR, Dexter JG, Blevins FT. Reconstruction of the anterior and posterior cruciate ligaments after knee dislocation: results using fresh-frozen nonirradiated allografts. Am J Sports Med 1999;27:189-96.

34. Jackson DW, Grood ES, Goldstein JD, et al. A comparison of patellar tendon autograft and allograft used for anterior cruciate ligament reconstruction in the goat model. Am J Sports Med 1993;21:176-85. 